\title{
Heart rate deflection point as an alternative method to identify the anaerobic threshold in patients with type 2 diabetes
}

\author{
Rodrigo Sudatti Delevatti ${ }^{\mathrm{a}, *}$, Ana Carolina Kanitz ${ }^{\mathrm{a}}$, Cristine Lima Alberton ${ }^{\mathrm{b}}$, \\ Patricia Dias Pantoja ${ }^{a}$, Elisa Corrêa Marson ${ }^{a}$, Carolina Dertzbocher Feil Pinho a, \\ Salime Chedid Lisboa ${ }^{a}$, Luciana Peruchena Bregagnol ${ }^{a}$, Luiz Fernando Martins Kruel ${ }^{a}$ \\ ${ }^{a}$ Exercise Research Laboratory, Physical Education School, Federal University of Rio Grande do Sul, Porto Alegre, RS, Brazil \\ b Department of Sports, Physical Education School, Federal University of Pelotas, RS, Brazil
}

\section{KEYWORDS}

Ventilatory threshold; Second ventilatory threshold; Heart rate deflection point;

Exercise;

Type 2 diabetes

\begin{abstract}
Aims: The purpose of this study was to evaluate the agreement between heart rate (HR) and treadmill velocity corresponding to the anaerobic threshold measured by second ventilatory threshold $\left(\mathrm{VT}_{2}\right)$ and the HR deflection point (HRDP) in patients with type 2 diabetes.

Materials and methods: Thirty-two sedentary patients $(56.1 \pm 7.7$ years) were evaluated. To determine the threshold values, patients performed an incremental treadmill test, with an initial velocity of $3 \mathrm{~km} \mathrm{~h}^{-1}$ for $3 \mathrm{~min}$, which was then increased by $1 \mathrm{~km} \mathrm{~h}^{-1}$ every $2 \mathrm{~min}$. The degree of agreement between $\mathrm{VT}_{2}$ and HRDP was analyzed using the Bland-Altman test. Results: Patients had a HR of $133 \pm 16 \mathrm{bpm}$ at $\mathrm{VT}_{2}$ and $133 \pm 18 \mathrm{bpm}$ at HRDP. Mean velocity corresponding to $\mathrm{VT}_{2}$ was $6.3 \pm 0.7 \mathrm{~km} \mathrm{~h}^{-1}$, and that corresponding to HRDP was $6.4 \pm 1.1 \mathrm{~km} \mathrm{~h}^{-1}$. There were no significant differences between the methods evaluated (HR: $p=0.78$; mean velocity: $p=0.57)$.

Conclusions: The present investigation concludes that there is an agreement between VT2 and HRDP methods for HR and treadmill velocity, and thus, either method may be used for these patients.

(c) 2014 Consell Català de l'Esport. Generalitat de Catalunya. Published by Elsevier España, S.L.U. All rights reserved.
\end{abstract}

\footnotetext{
* Corresponding author.

E-mail address: rsdrodrigo@hotmail.com (R.S. Delevatti).
} 


\section{PALABRAS CLAVE}

Umbral ventilatorio; Segundo umbral ventilatorio; Punto de desviación de la frecuencia cardiaca; Ejercicio; Diabetes tipo 2
Punto de desviación de la frecuencia cardíaca es una alternativa de método para identificar el umbral anaeróbico en pacientes con diabetes tipo 2

\begin{abstract}
Resumen
Objetivos: El propósito de este artículo fue evaluar la concordancia entre frecuencia cardíaca (FC) y velocidad en la cinta de correr correspondiente al umbral anaeróbico medido por el segundo umbral ventilatorio $\left(\mathrm{VT}_{2}\right)$ y por el punto de deflexión de la $\mathrm{FC}$ (PDFC) en pacientes con diabetes tipo 2.

Métodos: Se evaluaron treinta y dos pacientes sedentarios $(56,1 \pm 7,7$ años $)$ para determinar los valores de los umbrales, los pacientes realizaron una prueba de esfuerzo incremental a una velocidad inicial de $3 \mathrm{~km} \mathrm{~h}^{-1}$ durante $3 \mathrm{~min}$, con incrementos de $1 \mathrm{~km} \mathrm{~h}^{-1}$ cada $2 \mathrm{~min}$. Se analizó el grado de concordancia entre $\mathrm{VT}_{2}$ y PDFC mediante el test de Bland-Altman.

Resultados: Los pacientes mostraron una FC de $133 \pm 16 \mathrm{lpm}$ en $\mathrm{VT}_{2}$ y $133 \pm 18 \mathrm{lpm}$ en PDFC.

La velocidad media correspondiente a $V_{2}$ fue $6,3 \pm 0,7 \mathrm{~km} \mathrm{~h}^{-1}$ y la correspondiente a PDFC fue $6,4 \pm 1,1 \mathrm{~km} \mathrm{~h}^{-1}$. No hubo diferencias significativas entre los métodos evaluados ( $\mathrm{FC}: p=0,78$; velocidad media: $p=0,57$ ).

Conclusión: Esta investigación concluye que existe correspondencia entre los métodos $\mathrm{VT}_{2}$ y PDFC en FC y la velocidad media en la cinta de correr, por lo tanto, cualquiera de estos dos métodos puede ser usado en estos pacientes.

(C) 2014 Consell Català de l'Esport. Generalitat de Catalunya. Publicado por Elsevier España, S.L.U. Todos los derechos reservados.
\end{abstract}

\section{Introduction}

The physical exercise is considered as one of the main strategies for the type 2 diabetes management. ${ }^{1}$ Among these exercises, the aerobic training shows beneficial acute $e^{2,3}$ and chronic effects ${ }^{4-6}$ in the inflammatory, glycemic, lipids, pressoric and functional outcomes. However, most studies with aerobic training in this population ${ }^{4-12}$ have prescribed the training intensity based on percentages of peak oxygen uptake $\left(\% \mathrm{VO}_{2 \text { peak }}\right)$ and maximal heart rate $\left(\% \mathrm{HR}_{\max }\right)$, which can elicit different physiological responses for different individuals and that submaximal parameters such anaerobic threshold are better markers of the stress induced by physical exercise. ${ }^{13}$

The gold standard parameter for the aerobic training prescription is the anaerobic threshold (AT), ${ }^{14}$ because it represents the intensity of transition between the predominantly aerobic to predominantly anaerobic pathway. Besides providing a more precise knowledge of the metabolic status achieved by the patient during the exercise, the AT is also more responsive to training than the maximum parameters. ${ }^{13}$ In type 2 diabetes, this zone of metabolic transition deserves special attention, because it represents the intensity in which plasma glucose level reduces without a substantial increase in plasma glucagon concentrations, besides minimizing cardiac accident risk. ${ }^{15}$ From a practical point of view, it is important to know the AT for the exercise prescription not only for the traditional aerobic training, but also for the interval training with periodic excursions into "anaerobic" energy pathways. This type of training facilitates greater improvements in cellular signaling pathways involved in energy metabolism, improving sub-maximal and maximal exercise capacity, mitochondrial biogenesis, enzymatic markers associated with glycolysis, aerobic metabolism and beta-oxidation, anthropometry and quality of life better than aerobic exercise training. ${ }^{16,17}$ These changes seem to occur with less caloric expenditure and time spent than traditional aerobic exercise training. ${ }^{17}$

Despite the importance of using the AT for the exercise prescription, its traditional methods of determination (blood lactate and ventilatory method) do not present easy applicability. The ventilatory method is one of the more used methods in exercise sciences. The ventilatory curve and ventilatory equivalent analyses enable the determination of the break point at which the respiratory system is unable to effectively buffer $\mathrm{H}^{+}$ions, which leads to a disproportional increase in ventilation and carbon dioxide. This break point is known as the second ventilatory threshold $\left(\mathrm{VT}_{2}\right) .{ }^{18,19}$ However, the high cost of the equipment used to analyze breathing gases makes the method very expensive, limiting its practical application. ${ }^{20,21}$

A less expensive and more accessible alternative for the determination of AT can be achieved by analyzing heart rate behavior during incremental tests. This method was previously proposed by Conconi et al., ${ }^{22}$ and it is based on the relationship between the HR and the effort intensity. This relationship is partly linear and partly non-linear and the velocity in which exist a break point in the linearity, known as heart rate deflection point (HRDP), is associated with AT. ${ }^{22}$ Furthermore, HRDP can be measured with relatively simple equipment. ${ }^{23}$ In the literature, this method has been very investigated, showing association with AT in several studies. ${ }^{23-25}$ Notwithstanding, there is a gap in the literature regarding the use of HRDP for the determination of the AT in patients with type 2 diabetes. The practicality of this measure offers a distinct advantage over the second lactate threshold and the $\mathrm{VT}_{2}$, because need only of HR monitors.

Thus, the aim of this study was to analyze the agreement between the $\mathrm{VT}_{2}$ and HRDP methods for the treadmill velocity and HR in patients with type 2 diabetes. Our hypothesis 
was that the velocities and the HR values should correspond between both methods.

\section{Materials and methods}

\section{Subjects}

After approval of this study by the Research Ethics Committee of the Federal University of Rio Grande do Sul ( $\mathrm{n}^{\circ}$ : 108.997) and by the Research Ethics Committee of the Clinical Hospital of Porto Alegre ( $\left.n^{\circ}: 54475\right), 32$ subjects (14 male and 18 female) with type 2 diabetes and age $>30$ years (between 37 and 71 years) provided written consent for participating in this investigation. Patients with the following conditions were excluded from the sample: uncontrolled hypertension, autonomic neuropathy, severe peripheral neuropathy, proliferative diabetic retinopathy, severe nonproliferative diabetic retinopathy, decompensated heart failure, limb amputations, chronic renal failure (Modification of Diet in Renal Disease-glomerular filtration rate $<30 \mathrm{ml} / \mathrm{min}),{ }^{26}$ or any muscle or joint impairments that prevented individuals from engaging in physical exercise. The absence of these conditions was confirmed by medical history as well as by clinical and laboratory examinations. All patients had undergone electrocardiogram stress testing 6 months before the study.

\section{Experimental procedures}

Before performing the exercise tests proposed in this study, all patients underwent anthropometric measurements, fasting, blood sampling, and familiarization with the exercise test.

\section{Anthropometry}

An initial session was held to collect anthropometric data. Body mass and height measurements were obtained using an analog medical scale and a stadiometer (FILIZOLA; Sao Paulo, Brazil). Based on these values, the body mass index was calculated according to the following equation: Body mass index $=$ mass $(\mathrm{kg}) \times$ height $(\mathrm{m})^{-2}$. Hereafter, the measurement of the waist perimeter was obtained with an inextensible metallic tape (Cescorf; Porto Alegre, Brazil), at the midpoint between the iliac crest and the last rib.

\section{Blood analysis}

Blood samples $(4 \mathrm{ml})$ were obtained from the antecubital vein after fasting for $12-14 \mathrm{~h}$. The samples were collected in tubes with EDTA and were frozen at $-80^{\circ} \mathrm{C}$ as total blood (without centrifugation). After blood data collection, the levels of glycated hemoglobin were determined through high-performance liquid chromatography to characterize the glycemic control of the patients.

\section{Exercise test}

Exercise tests were conducted on a previously calibrated treadmill (Inbramed, Porto Alegre, Brazil) with an initial velocity of $3 \mathrm{~km} \mathrm{~h}^{-1}$ for $3 \mathrm{~min}$, with $1 \%$ inclination; the velocity was increased by increments of $1 \mathrm{~km} \mathrm{~h}^{-1}$ every $2 \mathrm{~min}$, until exhaustion. Heart rate was monitored every 10 s (Polar, Kajaani, Finland) and rate of perceived exertion was measured in the final $20 \mathrm{~s}$ of each stage (6-20 Borg Scale). Furthermore, during the test, oxygen uptake, carbon dioxide production $\left(\mathrm{VCO}_{2}\right)$, and ventilation $\left(\mathrm{V}_{\mathrm{E}}\right)$ were continuously monitored using a portable gas analyzer (VO2000 Gas Analyzer, Med Graphics) with sampling frequency of one sample every three breaths. Prior to each session, the portable gas analyzer was calibrated according to manufacturer's instructions. The assessment was considered valid when some of the following criteria were met at the end of the test: (1) estimated maximal heart rate was reached (220 - age); (2) a respiratory exchange ratio greater than 1.15 was achieved; and (3) a rating of perceived exertion of at least $18 .{ }^{27}$ All tests were performed in the presence of a cardiologist, at a controlled room temperature $\left(24-26^{\circ} \mathrm{C}\right)$.

\section{Criteria for determining the $\mathrm{VT}_{2}$ and HRDP}

The $\mathrm{VT}_{2}$ was obtained by determining the second inflection point in the $\mathrm{V}_{\mathrm{E}}$-by-intensity graph, and it was confirmed using the $\mathrm{CO}_{2}$ ventilatory equivalent $\left(\mathrm{V}_{\mathrm{E}} / \mathrm{VCO}_{2}\right) .{ }^{28}$ The HRDP was observed in the HR-by-intensity graph. ${ }^{22}$ The analysis were carried out by two independent, blinded, experienced exercise physiologists. The break points corresponding to the $\mathrm{VT}_{2}$ and HRDP were considered valid when both physiologists identified the same value. If there were no consensus, a third physiologist would be recruited. After his analysis, the break point was selected using the median of the points found by each exercise physiologist.

Data analysis was based on the HR and treadmill velocity corresponding to the break point determined by the $\mathrm{VT}_{2}$ and HRDP methods. The velocity was considered as the last velocity at which patients were exercising (at least $30 \mathrm{~s}$ before the break point).

\section{Statistical analysis}

For descriptive data, data were given as mean \pm standard deviation. Shapiro-Wilk's test was used to verify the normal distribution of the data. Comparisons between the HRDP method and the $\mathrm{VT}_{2}$ reference method were performed using the Bland-Altman method, which evaluates the potential existence of agreement or bias. Bland-Altman analysis uses means and standard deviations to evaluate differences between measurements acquired from the standard and new methods. By analyzing bias and limits of agreement, it is possible to evaluate whether the methods agree. Depending on the nature of the variable, a wide limit of agreement may represent the absence of agreement between methods. A bias close to zero represents an agreement between methods. The heteroscedasticity of the Bland-Altman plots was analyzed by performing linear regression analysis.

\section{Results}

Characteristics of the patients are presented in Table 1. All patients performed the tests appropriately, and no adverse effects were recorded. 
Table 1 Patients characteristics.

\begin{tabular}{lc}
\hline Age (years) & $56.1 \pm 7.7$ \\
Duration of DM2 (years) & $7.4 \pm 5.6$ \\
HbA1c (\%) & $7.8 \pm 2.3$ \\
Body mass $(\mathrm{kg})$ & $85.6 \pm 14.6$ \\
Body mass index $\left(\mathrm{kg} . \mathrm{m}^{-2}\right)$ & $32.1 \pm 4.2$ \\
Waist circumference $(\mathrm{cm})$ & $106.5 \pm 11.5$ \\
Medication & \\
$\quad$ Metformin & 32 \\
Sulphonylurea & 9 \\
DPP-4-inhibitors & 2 \\
Insulin & 7
\end{tabular}

DPP-4: dipeptidyl peptidase-4.

Values of age, duration of DM2 and anthropometric measures are expressed as the mean \pm SD.

Values of $\mathrm{HbA1C}$ are expressed as \%.

Values of medication are expressed by $n$.

Although all patients had been able to carry out the incremental test, five from the thirty-two patients (15.6\%) showed no signs of an HRDP.

Heart rate in second ventilatory threshold (HRVT2 was $133 \pm 16 \mathrm{bpm}$ and HRDP was $133 \pm 18 \mathrm{bpm}$. Mean velocity corresponding to $\mathrm{VT}_{2}$ was $6.3 \pm 0.7 \mathrm{~km} \mathrm{~h}^{-1}$, and that corresponding to HRDP was $6.4 \pm 1.1 \mathrm{~km} \mathrm{~h}^{-1}$.

According to the Bland-Altman analysis, there were no significant differences between the $\mathrm{VT}_{2}$ and HRDP methods for the HR and the $r$-value between the difference and the corresponding average was low $(r=0.07 ; 95 \% \mathrm{Cl}$ : -2.2 to $2.8 \mathrm{bpm} ; p=0.78$; Fig. 1). For mean treadmill velocity, also there were no significant differences between methods and the $r$-value was low $\left(r=0.26 ; 95 \% \mathrm{Cl}:-0.2\right.$ to $0.3 \mathrm{~km} \mathrm{~h}^{-1}$; $p=0.57$; Fig. 2). The limits of agreement represent a small amplitude range, with the bias close to zero. Hence, an agreement is assumed between the two methods used to determine AT.

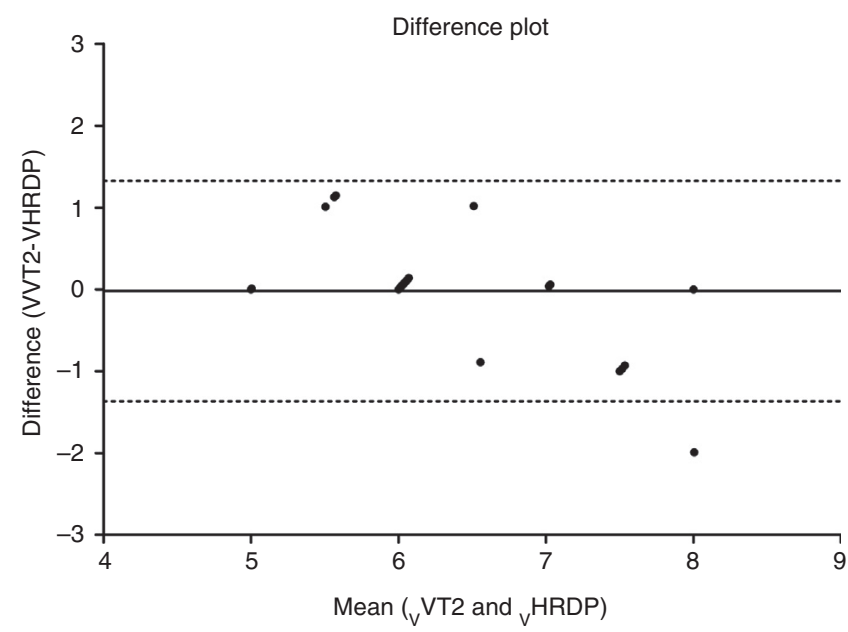

Figure 1 Bland-Altman test for velocities corresponding to the second ventilatory threshold $\left(\mathrm{VT}_{2}\right)$ and heart rate deflection point (HRDP), in sedentary patients with type 2 diabetes. The solid line near zero represents bias $(-0.018)$, and the dotted lines represent the limits of agreement $(-1.366$ to 1.328$)$.

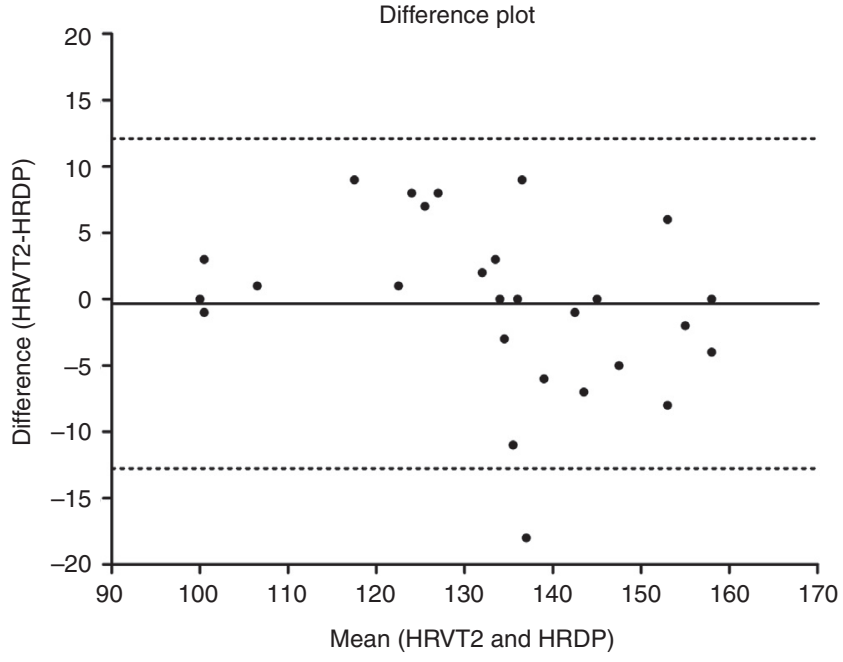

Figure 2 Bland-Altman test for heart rate values corresponding to the second ventilatory threshold $\left(\mathrm{VT}_{2}\right)$ and heart rate deflection point (HRDP), in sedentary patients with type 2 diabetes. The solid line near zero represents bias $(-0.333)$, and the dotted lines represent the limits of agreement $(-12.765$ to 12.098).

\section{Discussion}

Results from the present study indicate an agreement between the HRDP and $\mathrm{VT}_{2}$ methods in sedentary patients with type 2 diabetes, according to our hypothesis. This agreement was observed by means of two parameters, a physiological (HR) and a physical one (mean velocity). The similar HR verified in both methods (133 bpm) favors the use of HRDP because the control of the training may be carried out with a simple HR monitor for an adequate intensity prescription. Since the HR is a physiological variable, it is very responsive to the metabolic status of the patients. In addition, it may be used to modulate the training intensity in accordance to the current situation of the patient, with adjustments in the intensity based on previous effort or rest.

According to our findings, Kruel et al. ${ }^{25}$ found no difference between HRVT2 and HRDP. This study evaluated young active women running in treadmill, as well as performing a stationary running on land and a stationary running in water. Besides the lack of difference in the AT between methods, another interesting result of this study was the similarity between the AT found in treadmill running and the one found in stationary running on land, which adds to the literature the possibility of performing a more accessible test, that does not require the treadmill to determine the AT. Nevertheless, this protocol has not been performed in patients with type 2 diabetes or with other complications, being this, a gap in the literature, that should be more investigated through accurate and accessible forms of manipulation of the physical training variables.

In order to expand the possibilities of an adequate training prescription for this population, it was also verified the treadmill velocity corresponding to the AT determined by both methods, since the patients can carry training at pre-determined intensities without using an HR monitor. Thus, an alternative way could be the performance of the 
incremental test on a treadmill with the HR monitor for the determination of the AT and posterior training prescription based on the velocity corresponding to the HRDP. However, since the velocity is a physical variable, it is not modulated by physiological alterations, fact that may compromise the training when, due to certain factors, such as time, fatigue, sleep alterations or psychological stress, patients vary widely the physiological condition in which they perform the training sessions. Nevertheless, if the training is structured and conducted in a routine, with controlled environmental conditions, the velocity related to the HRDP may be a valuable parameter during the training prescription. Despite the agreement observed between the methods of AT determination, it should be considered that approximately $15 \%$ from the patients did not show HRDP. Although this percentage is low, it is important to consider other simple and effective ways to prescription of training intensity in this group of patients.

The study by Sales et al. ${ }^{29}$ proposed a non-invasive AT determination in patients with type 2 diabetes through the heart rate variability threshold. This method presented agreement with the lactate threshold method, considered as gold standard. Despite the positive results observed, the extrapolation of the findings regarding the heart rate variability threshold is difficult because this method needs specific HR monitor (with R-R intervals register) and software for data analysis. In addition, this study evaluated only nine patients with an optimal glycemic control $(\mathrm{HbA1c}=6.8 \pm 1.3 \%)$ with the protocol performance in cycle ergometer. In the present study, 27 patients with a common clinical situation to the most patients with type 2 diabetes were analyzed, comprised by sedentary men and women with a poor glycemic control (HbA1C $=7.8 \pm 1.3 \%$ ), improving the external validity of the findings. In addition, the HRDP is a low cost method with an easy application.

Clinically, our results have great relevance because they indicate the need to investigate agreement between different methods of determining the AT in patients with type 2 diabetes. That is because these measurements may be impaired by metabolic disorders, a common occurrence in diabetes, which can lead to different physiological responses during incremental exercise. In addition, scientific literature supports the benefits of prescribing exercises with intensities corresponding to the AT in this population. ${ }^{30}$ Besides the possible application of a HRDP to determine the AT in patients with type 2 diabetes, it is important that both methods show similar results during treadmill exercise, as the walking/running is the most used modality of aerobic training in investigations on type 2 diabetes. ${ }^{31}$ In addition, the walking or running exercises recruit a larger muscle mass than other types of aerobic training, such as the cycle ergometer; this fact improves the body composition and glycemic control. ${ }^{14}$

In conclusion, the present investigation verified an agreement between the HRDP and $\mathrm{VT}_{2}$ methods in sedentary patients with type 2 diabetes, suggesting that the HRDP may be used by physical education professionals who work with this population. It is important to introduce and to improve the prescription and control of training intensity by the AT because the knowledge of this metabolic transition point increases the safety and effectiveness of exercise interventions for controlling type 2 diabetes.

\section{Conflict of interest}

Authors declare that they don't have any conflict of interests.

\section{Acknowledgements}

We are grateful to the volunteers who participated on this study and to CAPES, CNPq and FAPERGS.

\section{References}

1. American Diabetes Association. Standards of medical care in diabetes. Diabetes Care. 2014;37 Suppl. 1: S14-80.

2. Terada T, Friesen A, Chahal BS, Bell GJ, McCargar LJ, Boulé NG. Exploring the variability in acute glycemic responses to exercise in type 2 diabetes. J Diabetes Res. 2013;2013:591574.

3. Asano RY, Sales MM, Browne RAV, Moraes JFVN, Júnior HJC, Moraes MR, et al. Acute effects of physical exercise in type 2 diabetes: a review. World J Diabetes. 2014;5: 659-65.

4. Abd El-Kader SM, Gari AM, Salah El-Den AEM. Impact of moderate versus mild aerobic exercise training on inflammatory cytokines in obese type 2 diabetic patients: a randomized clinical trial. Afr Health Sci. 2013;13.

5. Belli T, Ribeiro LFP, Ackermann MA, Baldissera V, Gobatto CA, Galdino Da Silva R. Effects of 12 -week overground walking training at ventilatory threshold velocity in type 2 diabetic women. Diabetes Res Clin Pract. 2011;93:337-43.

6. Li J, Zhang W, Guo Q, Liu X, Zhang Q, Dong R, et al. Duration of exercise as a key determinant of improvement in insulin sensitivity in type 2 diabetes patients. Tohoku J Exp Med. 2012;227:289-96.

7. Cauza E, Hanusch-Enserer U, Strasser B, Ludvik B, MetzSchimmerl S, Pacini G, et al. The relative benefits of endurance and strength training on the metabolic factors and muscle function of people with type 2 diabetes mellitus. Arch Phys Med Rehabil. 2005;86:1527-33.

8. Sigal RJ, Kenney GP, Boulé NG, Wells GA, Prud'Homme D, Fortier $M$, et al. Effects of aerobic training: resistance training, or both on glycemic control in type 2 diabetes. Ann Intern Med. 2007; 147:357-69.

9. Church TS, Blair SN, Cocreham S, Johannsen N, Johnson W, Kramer K, et al. Effects of aerobic and resistance training on hemoglobin A1c levels in patients with type 2 diabetes. JAMA. 2010;304:2253-62.

10. Asa C, Maria S, Katharina SS, Bert A. Aquatic exercise is effective in improving exercise performance in patients with heart failure and type 2 diabetes mellitus. Evid Based Complement Alternat Med. 2012;2012:349209.

11. Karstoft K, Winding K, Knudsen SH, Nielsen JS, Thomsen C, Pedersen BK, et al. The effects of free-living intervalwalking training on glycemic control. Body composition, and physical fitness in type 2 diabetes patients. Diabetes Care. 2012;36:228-36.

12. Kadoglou NPE, Fotiadis G, Kapelouzou A, Kostakis A, Liapis CD, Vrabas IS. The differential anti-inflammatory effects of exercise modalities and their association with early carotid atherosclerosis progression in patients with Type 2 diabetes. Diabet Med. 2013;30:e41-50.

13. Meyer T, Lucia A, Earnest CP, Kindermann W. A conceptual framework for performance diagnosis and training prescription from submaximal gas exchange parameters - theory and application. Int J Sports Med. 2005;26:38-48. 
14. Belli T, Ackermann MA, Ribeiro LF, Langeani R, Galdino da Silva $\mathrm{R}$, Baldissera V. Lactate and ventilatory thresholds in type 2 diabetic women. Diabetes Res Clin Pract. 2007;76:18-23.

15. Kawaji K, Fujita Y, Yajima M, Kubo H. Usefulness of anaerobic threshold in estimating of exercise for diabetics. Diabetes Res Clin Pract. 1989;6:303-9.

16. Kirsten AB, Scott CH, George JFH, Suzanne NB, Martin JG. Six sessions of sprint interval training increases muscle oxidative potential and cycle endurance capacity in humans. J Appl Physiol. 2005;98:1985-90.

17. Tremblay A, Simoneau JA, Bouchard C. Impact of exercise intensity on body fatness and skeletal muscle metabolism. Metabolism. 1994;43:814-8.

18. Binder RK, Wonisch M, Corra U, Cohen-Solal A, Vanhees L, Saner $\mathrm{H}$, et al. Methodological approach to the first and second lactate threshold in incremental cardiopulmonary exercise testing. Eur J Cardiovasc Prev Rehabil. 2008;15:726-34.

19. Reinhard U, Muller PH, Schmulling RM. Determination of anaerobic threshold by the ventilation equivalent in normal individuals. Respiration. 1979;38:36-42.

20. Silva GSF, Deresz CS, Lima PRJ. Associação entre limiares ventilatórios e percepção do esforço. R bras Ci e Mov. 2006;14:79-86.

21. Azevedo PHSM, Garcia A, Duarte JMP, Carrara VKP, Marson RA. Limiar Anaeróbio e Bioenergética: uma abordagem didática. Rev Educ Fis. 2009;20:453-64.

22. Conconi F, Ferrari M, Ziglio PG, Droghetti P, Codeca L. Determination of the anaerobic threshold by a noninvasive field test in runners. J Appl Physiol Respir Environ Exerc Physiol. 1982;52:869-73.

23. Marques-Neto SR, Maior AS, Maranhão Neto GA, Santos EL. Analysis of heart rate deflection points to predict the anaerobic threshold by a computerized method. J Strength Cond Res. 2012;26:1967-74.

24. Alberton CL, Tartaruga MP, Pinto SS, Cadore EL, Antunes AH, Finatto $P$, et al. Vertical ground reaction force during water exercises performed at different intensities. Int J Sports Med. 2013;34:881-7.

25. Kruel LMK, Beilke DD, Kanitz AC, Alberton CL, Antunes AH, Pantoja PD, et al. Cardiorespiratory responses to stationary running in water and on land. J Sports Sci Med. 2013;12:594-600.

26. Meara E, Chong K, Gardner R, Jardine AG, Neill JB, McDonagh TA. The Modification of Diet in Renal Disease (MDRD) equations provide valid estimations of glomerular filtration rates in patients with advanced heart failure. Eur J Heart Fail. 2006;8:63-7.

27. Howley ET, Basset DR Jr, Welch HG. Criteria for maximal oxygen uptake: review and commentary. Med Sci Sports Exerc. 1995;27:1292-301.

28. Wasseman K, Whipp BJ, Koyal SN, Beaver WL. Anaerobic threshold and respiratory gas exchange during exercise. J Appl Physiol. 1973;35:236-43.

29. Sales MM, Campbell CSG, Morais PK, Ernesto C, Soares-Cadeira LF, Russo P, et al. Noninvasive method to estimate anaerobic threshold in individuals with type 2. Diabetol Metab Syndr. 2011;3:1.

30. Brun JF, Bordenave S, Mercier J, Jaussent A, Picot MC, Prefaut C. Cost-sparing effect of twice-weekly targeted endurance training in type 2 diabetics: a oneyear controlled randomized trial. Diabetes Metab. 2008;34:258-65.

31. Oliveira CO, Simões M, Carvalho J, Ribeiro J. Combined exercise for people with type 2 diabetes mellitus: a systematic review. Diabetes Res Clin Pract. 2012;98:187-98. 